\title{
A RELAÇÃO PROFESSOR/ALUNO E SUA INFLUÊNCIA NO PROCESSO DE ENSINO E APRENDIZAGEM DE MATEMÁTICA NO ENSINO FUNDAMENTAL
}

\section{ARTIGO ORIGINAL}

COSTA, Joelma Cerdeira ${ }^{1}$, NUNES, Narciso Natividade ${ }^{2}$, ARCHANJO, Paulo César Vieira $^{3}$

COSTA, Joelma Cerdeira. NUNES, Narciso Natividade. ARCHANJO, Paulo César Vieira. A relação professor/aluno e sua influência no processo de ensino e aprendizagem de matemática no Ensino Fundamental. Revista Científica Multidisciplinar Núcleo do Conhecimento. Ano 04, Ed. 12, Vol. 02, pp. 151-166. Dezembro de 2019. ISSN: 2448-0959, Link de acesso: https://www.nucleodoconhecimento.com.br/educacao/aprendizagem-de-matematica, DOI: 10.32749/nucleodoconhecimento.com.br/educacao/aprendizagem-dematematica

\section{RESUMO}

O presente trabalho apresenta discussões e reflexões sucintas sobre a relação Professor/Aluno e sua influência no processo Ensino/Aprendizagem de Matemática, como parte de uma pesquisa de Mestrado em desenvolvimento, tendo uma abordagem qualitativa e bibliográfica para interpretação dos resultados, baseada em teóricos conceituados que expressam o processo Ensino-Aprendizagem em sua

\footnotetext{
${ }^{1}$ Mestrando em Ciências da Educação pela Universidade Saint Alcuin of York Anglican College - Chile; Especialista em Educação Inclusiva pela Faculdade de Ciências Administrativas e de Tecnologia de RondôniaFatec-Rondônia; Especialista Anos Iniciais do Ensino Fundamental- UNOPAR; Licenciada em Pedagogia pela Universidade Federal do Amazonas - UFAM.

${ }^{2}$ Mestrando em Ciências da Educação pela Universidade Saint Alcuin of York Anglican College - Chile; Especialista em Metodologia da Interdisciplinaridade pelo Centro Universitário Barão de Mauá - Ribeirão Preto - SP; Licenciado em Matemática pela Universidade do Estado do Amazonas - UEA no Centro de Estudos superiores de Parintins - CESP.

${ }^{3}$ Doutorado em Ciências do Ambiente e Sustentabilidade na Amazônia. Mestrado em Gestão E Consultoria Ambiental. Especialização em andamento em Especialização em Gestão Educacional. Especialização em Docência Do Ensino Superior. Graduação em Licenciatura Plena Em História. Graduação em Ciências Sociais.
}

RC: 42251

Disponível em: https://www.nucleodoconhecimento.com.br/educacao/aprendizagemde-matematica 
magnitude, com finalidade de compreender os fenômenos presentes na relação professor/aluno. Dessa forma, apresenta-se a relação presente entre o professor e o aluno no contexto escolar, a imagem que os alunos têm de seu docente e os aspectos presentes nessa relação. Assim, esta pesquisa, busca desvendar os fenômenos desse processo proximal no contexto escolar, pois pensa-se na relação professo/aluno como uma possibilidade de intervenção em que o ensino se aproxima do aluno a partir do momento que este cria laços com seu professor, de modo a contribuir para sua formação, tanto escolar quanto social.

Palavras-Chave: Professor/aluno, ensino/aprendizagem, matemática.

\section{INTRODUÇÃO}

Atualmente o contexto escolar apresenta lacunas frente o processo EnsinoAprendizagem de Matemática, que caem como reais desafios a serem superados pela equipe escolar. Fatores como ausência de materiais didáticos, complexidade na utilização de recursos existentes no ambiente escolar, a vida social do aluno e, outros, são alguns desses desafios a serem superados, onde o principal agente a encarar cotidianamente esses fatos é o professor em sala de aula.

Apesar de tantos desafios, acredita-se que a aprendizagem é um processo que não depende apenas dos recursos materiais existentes, mas que está implícita em outros processos que o rodeiam no contexto escolar. Nessa perspectiva, entende-se que o professor é um agente ativo na construção formativa do aluno, que a partir dessa relação, o estudante também passa a ser ativo no processo de sua aprendizagem.

Nesse sentido, o professor é nada mais do que um mediador na construção de conhecimentos dos alunos, sendo capaz de produzir muito mais do que conhecimentos científicos, mas atrelando em cada indivíduo aspectos sociais, que, nessa abordagem são considerados tão importantes quanto os conteúdos aprendidos, ou apreendidos, em sala de aula, de forma mecânica e sistemática.

RC: 42251

Disponível em: https://www.nucleodoconhecimento.com.br/educacao/aprendizagemde-matematica 
Dessa forma, este trabalho traduz uma camada do âmbito educacional baseada na literatura dos processos existentes no ambiente escolar, mais especificamente sobre dificuldades e possibilidades presentes nesse contexto. Deixa-se explicito nessa abordagem a relação que o professor estabelece com os alunos em sala de aula, considerando que esse processo garante respostas adequadas à maneira que se deve superar todos os desafios cotidianos.

Dessa forma, a pesquisa se apresenta em três partes consideradas importantes para a abordagem dos seus objetivos: primeiramente, busca-se interpretar de que maneira é possível estabelecer uma relação no cotidiano escolar, bem como as suas consequências. Consequentemente, pretende-se identificar as imagens que os alunos estabelecem do seu professor de matemática, esta determinada inconscientemente, a partir de suas atitudes e sua postura perante o processo de ensino e aprendizagem da disciplina. Por fim, apresenta-se os aspectos presentes no processo da relação professor-aluno, as verdades implícitas nessa relação e aquilo que está oculto diante desse processo.

\section{RELAÇÃO PROFESSOR/ALUNO ESTABELECIDA NO CONTEXTO ESCOLAR}

O cotidiano escolar apresenta diferentes situações no tangente ao processo ensino/aprendizagem da Matemática, sobretudo para alunos de Ensino Fundamental, que é a etapa que necessita ser solidificada, a fim de se chegar à etapa posterior com o mínimo de carência possível dos conceitos básicos desta disciplina. Nesse caso, há certos recursos didáticos que contribuem para tal aprendizado, mas quando a escola não dispõe dos mesmos ou quando o possuem, mas não se tem o conhecimento adequado de sua utilização, afeta consideravelmente o processo de ensino-aprendizagem.

No entanto, as práticas docentes estão entre as situações que mais causam dificuldades à aprendizagem dos alunos. De maneira geral, o tratamento dado pelo professor de Matemática a seus alunos influencia na aquisição de conhecimento por

RC: 42251

Disponível em: https://www.nucleodoconhecimento.com.br/educacao/aprendizagemde-matematica 
parte dos mesmos, considerando, assim, que a relação professor/aluno no contexto da aprendizagem é de fundamental importância para o processo educacional.

Digamos também que, ao enfatizar o intercâmbio intelectual com os alunos, o docente entende que eles são seres que existem no mundo de maneira mais ampla, que vai além da aula de matemática: não é nem de longe desprezível o valor educativo implícito nessa consideração (SADOSVKY, 2010, p. 17).

Os conteúdos de matemática de Ensino Fundamental devem ser trabalhados bem mais no âmbito qualitativo do que quantitativo, aproximando o máximo possível dos seus significados, pois estes são a base fundamental da matemática para os demais níveis de ensino. Nesse sentido, Drouet (2006, p. 27), afirma que o aluno está pronto "para aprender, quando apresenta um conjunto de condições, capacidades, habilidades e aptidões consideradas como pré-requisitos para o início de qualquer aprendizagem".

Isso significa dizer que todo o conhecimento adquirido nesse nível de ensino não servirá apenas para o ano letivo em questão, mas será a base primordial do Ensino Médio ou de qualquer seguimento posterior no âmbito educacional. Nesse caso, o aluno estará mais bem preparado para dar continuidade nos anos posteriores de seus estudos. "[...] As estratégias de ação são motivadas pela projeção do indivíduo no futuro (suas vontades, suas ambições, suas motivações e tantos outros fatores), tanto no futuro imediato quanto no futuro longínquo, até o que poderia ser o momento final" (D’AMBROSIO, 2012, p. 21).

Além disso, é dever do docente ajudá-los na construção desses conhecimentos para que a aprendizagem seja eficaz. Dessa forma, cabe ao professor o papel de tentar preencher as lacunas existentes quanto ao significado dos conteúdos ensinados em sala de aula em relação com a vida cotidiana do aluno, tentando fixar esses conceitos para que o mesmo o compreenda no seu dia-a-dia, a fim de gerar situações de discussão, estimular e, despertar no aluno o querer aprender.

[...] Ora, considerar os estudantes sujeitos pensantes, com ideias próprias e férteis, capazes de produzir novas ideias, é aceitar que eles também precisam pensar "intimamente", pensar "em rascunho", ensaiar, explorar, rabiscar, "dar-

RC: 42251

Disponível em: https://www.nucleodoconhecimento.com.br/educacao/aprendizagemde-matematica 
se o luxo" de relacionar suas questões com aquilo que é significativo pra eles, apelar para representações que os ajudem a "ver" (SADOVSKY, 2010, p. 84).

Esta postura docente deve ser cautelosa, deve conciliar tempo e conteúdos a serem ensinados e ainda encontrar mecanismos para despertar a atenção dos alunos para o conteúdo que está sendo ensinado, uma vez que, se não há empenho por parte do aluno, o conteúdo pode tornar-se sem significado e desinteressante.

É importante que o professor mantenha uma relação mais próxima com os alunos, se aproximando também da realidade que os rodeia e dos fatores, sejam externos ou internos, que impliquem diretamente em suas dificuldades de aprender, a fim de que as perceba mais a fundo, possibilitando ao docente maior eficácia em sua contribuição, pois, a partir disso, este pode trabalhar o conhecimento conforme o cotidiano dos estudantes e suas crises. "Trata-se de adaptar o conhecimento a uma maneira compatível com o fluxo natural em que a turma está inserida naquele momento" (CASASSUS, 2008, p. 30). Essa adaptação nada mais é do que estabelecer relações com seus alunos para ganhar o afeto e a confiança deles, na tentativa de fazê-los perceber a possibilidade de lidar com seus desafios de frente.

O simples fato de o professor se direcionar a cada aluno, "passeando" na classe após a exposição de conteúdos e propor situações problemas, onde direciona-se a quantos sentirem dificuldades, facilita para que o docente perceba possíveis dificuldades de cada um, além de possibilitar aos indivíduos, um possível diálogo, que é o principio de se alcançar esse laço afetivo e, dessa forma, compreendendo o lado do aluno, o docente se vê mais preparado para ajudá-lo. Para Casassus (2008, p.32), "essa capacidade sensível de entendê-los e pôr-se no lugar deles é essencial para induzir o processo de aprendizagem".

Nessa perspectiva, na medida em que o professor encontra os caminhos cabíveis para manter uma relação que contribua para o processo de ensino/aprendizagem, seus alunos perceberão a atenção que está sendo criada naquele momento para com eles e, sendo assim, o processo de ensino de matemática pode tomar um rumo 
muito importante e decisivo para a aprendizagem destes, que ao sentir a necessidade de ajuda, terão alguém para lhes ajudar.

Além disso, criar laços afetivos com os alunos permitirá ao docente ganhar maior confiança pelas crianças, dando passos cada vez maiores para penetrar no lado emocional do indivíduo, o qual permitirá que este se sinta capaz de produzir seus próprios conhecimentos e a buscar saídas para possíveis problemas, pois para o processo de ensino/aprendizagem se faz necessário que, tanto o aluno quanto o professor, sejam ativos em seu desenvolvimento. Dessa forma, a relação que o professor estabelece com seus alunos na classe implica na melhor aquisição dos conteúdos de Matemática a serem estudados, pois, pode despertar o interesse dos mesmos em aprendê-la.

Nesse sentido, o docente deve proporcionar um ambiente em que os alunos sintam prazer e interesse pelas aulas de matemática, pois trata-se de uma disciplina considerada difícil, compreendida somente por aqueles que têm maior capacidade.

\footnotetext{
Historicamente, a matemática é tida como uma disciplina difícil, na qual poucos têm sucesso e que causa, em muitos, certo temor. Para essas pessoas, a Matemática é considerada como a disciplina que oferece maiores dificuldades na escola, e o bom desempenho nessa área se reserva a pessoas mais capazes (TORISU E FERREIRA, 2009, p. 172).
}

Mas isso depende em parte da prática docente. Cabe ao professor estimular os alunos, manifestando o seu interesse pelo aprendizado deles e incentivando-os, criando um ambiente agradável de afetividade, de modo que se sintam importantes e confiantes em si mesmos. Isso ocorre quando a aula de Matemática é interessante, despertando o interesse dos alunos em aprendê-la, relacionando os conceitos matemáticos com o contexto sociocultural, usando situações-problema do cotidiano. "[...] Nessa abordagem, a função do professor é criar condições para que o aluno possa exercer a sua ação de aprender participando de situações que favoreçam isso" (D'AMBROSIO, 2012, p. 25).

RC: 42251

Disponível em: https://www.nucleodoconhecimento.com.br/educacao/aprendizagemde-matematica 
A postura docente adotada em relação à Matemática pode permitir aos alunos percebê-la como uma ferramenta para a resolução de problemas do cotidiano, pode fazer com que os alunos sintam interesse em aprender a Matemática porque saberão como e onde aplicar o que foi aprendido em sala de aula. De acordo com Drouet (2006, p.10) "O fato de querer aprender garante à criança um maior sucesso na aquisição de conhecimentos, habilidades ou técnicas. O interesse é, portanto, a mola propulsora da aprendizagem".

Além disso, quando não é proporcionado um ambiente onde a relação do professor com os alunos não oferece uma aprendizagem significativa, as aulas tornam-se monótonas, desagradáveis, entediantes, levando assim, a aprendizagem ao fracasso, "já que muitas vezes ela é consequência do tédio produzido por aulas pouco interessantes" (CASASSUS, 2008, p.30).

Se o professor mantém uma relação de confiança com seus alunos, as chances de compreensão dos conceitos matemáticos aumentam consideravelmente, leva-os a perceberem a importância destes para resolução de problemas práticos do dia a dia e, dessa forma, eles sentirão o desejo de aprender, gerando maior interesse pela matéria e garantindo maior aquisição de conhecimento.

O aluno, além de ganhar interesse por aprender a Matemática, acaba por percebê-la válida na construção da sua vida social, deixando de lado a percepção de que a matemática é uma disciplina pronta, desenvolvida por fórmulas já prontas, pois "[...] a vitalidade da Matemática deve-se também ao fato de que, apesar de seu caráter abstrato, seus conceitos e resultados têm origem no mundo real e encontram muitas aplicações em outras ciências e em inúmeros aspectos da vida diária" (BRASIL, 1997, p. 27).

Um dos maiores desafios aqui, mesmo que a relação seja aceita pelos alunos como forma de interagir também com o conhecimento, é fazer com que estes tenham a consciência da importância do estudo da matemática para sua vida, segundo Sadovsky (2010, p. 15) "a tarefa está longe de ser simples, porque muitos 
estudantes mostram que não podem, que não têm interesse, que não querem," Dessa forma, a dificuldade está em fazê-los perceber que não é bem dessa maneira que as coisas acontecem, mas para isso, é essencial que o docente já tenha criado um laço de confiança entre eles, a fim de que este tenha certa autoridade em aconselhar.

Outra forma de atrair a atenção dos alunos é questionando-os, ou ainda, fazê-los resolver problemas no quadro ou algo parecido, pois essa postura permite maior atenção dos mesmos às aulas, além de garantir maior segurança ao tentar resolver esses problemas, pois saberão que seu professor os ajudará.

Mas, apesar de tudo, tais fatores não são tão profundos quando comparados à relação Professor/Aluno no contexto escolar, pois essa interação é o elo entre o saber do professor e os alunos, que permite perceber a matemática no cotidiano, que insere o aluno na prática social como autênticos cidadãos e, dessa forma, a relação criada em sala de aula, transmite um conteúdo que vai além daquilo exposto na classe e, abrange todas as bases dos indivíduos.

Há outro fator que, para haver maior eficácia no processo de ensino e aprendizagem matemática, não pode ser desconsiderado: o professor precisa dominar o conteúdo, de maneira que deixe claro o que se pretende obter a partir dos objetivos. Para Casassus (2008, p. 28) "para transmitir o gosto pelo conhecimento, um professor precisa dominar os conteúdos de sua disciplina".

No entanto, não basta que o docente seja bem dotado de saberes matemáticos, se no fim de tudo este não é capaz de proporcionar um ambiente onde a relação dele com os seus alunos seja, não só a saída para solucionar problemas de cognição dos alunos, mas a mola que permite desencadear maior aquisição de conhecimento e, dessa forma, não se pode deixar passar por desapercebida essa ideia, pois entende-se que a relação Professor/Aluno é de fundamental importância para que haja uma aquisição de conhecimento mais eficaz e, que esta, não contribui somente para o desenvolvimento do aluno em sala de aula, mas em sua totalidade.

RC: 42251

Disponível em: https://www.nucleodoconhecimento.com.br/educacao/aprendizagemde-matematica 


\section{AS IMAGENS QUE OS ALUNOS TÊM DO PROFESSOR DE MATEMÁTICA}

O contato do professor com alunos diariamente no contexto escolar permite, inconscientemente, que estes criem uma imagem dele, mediante suas atitudes, metodologia, relação proximal. Diante disso o professor passa a ser visto conforme as qualidades e características que manifesta cotidianamente na convivência com seus alunos e, essa visão se estende também à disciplina que este ministra.

Geralmente, quando se tem em vista o professor de matemática, os alunos já têm certo temor, não porque ele possa ser ruim, mas por ministrar a disciplina que, de certa forma, causa temor a muitos e, dessa maneira, a imagem da disciplina se estende ao professor que a ministra, pois, "a representação de um determinado objeto abarca tanto a construção da representação como a possibilidade de operar com essa representação, efetuando transformações regidas pelas leis do registro na qual se representa" (SADOVSKY, 2010, p. 31).

No entanto, no decorrer da convivência no contexto escolar, essas ideias vão sofrendo transformações conforme o professor se mostra construtivo na aquisição de conhecimento do aluno, pois este acaba percebendo que não é a disciplina que implica diretamente na dificuldade de aprendê-la, mas que se o docente é nesse ato um mediador no seu amadurecimento, o aluno o terá como um companheiro. "Há, portanto, uma questão de confiança como pano de fundo do tipo de vínculo estabelecido com a interação entre o aluno e o docente" (SADOVSKY, 2010 p. 31).

Essas ideias decorrem da relação Professor/Aluno no lado mais afetivo da convivência onde, de um lado, um percebe o outro como um apoio em seu crescimento, fazendo com que, de outro lado, este se sinta estimulado a ajudar e contribuir, não somente em questão de conteúdos a serem abordados em sala de aula, mas em sua totalidade, de modo mais amigável possível, pois a emoção faz com que os indivíduos reflitam sobre as situações que thes rodeiam, ainda se as abordagens do professor sejam, à primeira vista, um tanto rigorosa.

RC: 42251

Disponível em: https://www.nucleodoconhecimento.com.br/educacao/aprendizagemde-matematica 
$O$ fato de o aluno se submeter às intervenções e à autoridade do professor o faz percebê-lo como um amigo, onde será compreendido pelos alunos que suas intervenções serão para crescimento e amadurecimento de cada um como ser social e autêntico. Para Sadovsky (2010, p. 17), "o aluno pode considerar as intervenções do professor em relação às suas ideias como contribuições que as alimentam, as modificam e o ajudam a elaborar novas conexões".

Nesse contexto, trata-se de falar da relação Professor/Aluno tendo como o ponto de partida as emoções, criadas nesse ambiente, onde o professor passa a ser visto pelos seus alunos como um administrador de sonhos. Segundo Guerra e Cosenza (2011, p.75):

As emoções são fenômenos que assinalam a presença de algo importante ou significante em um determinado momento na vida de um indivíduo. Elas se manifestam por meio de alterações na sua fisiologia e nos seus processos mentais e mobilizam os recursos cognitivos existentes, como a atenção e a percepção.

Para Casassus (2008, p. 30) "a emoção é mais do que a simples experiência fisiológica ou psicológica. É uma energia vital, que liga os acontecimentos do mundo externo com o mundo interno de cada um de nós". Assim, quando é manifestada a afetividade nesse processo, o docente passa a ser visto, não somente como o professor que está ali para ensinar o que está como proposta no currículo escolar, mas é visto pelos seus alunos como aquele que vai encaminhá-los a um passo mais seguro na sua construção como cidadãos.

Nesse sentido, a emoção é um fator fundamental e indispensável de interação do professor com os alunos em sala de aula, pois, permite entender que a visão do aluno em relação ao docente ultrapassa a concepção de que ele é um mediador, não somente em sala de aula, mas de uma parcela da sua vida pessoal e social. Dessa forma, se o professor tiver uma boa convivência com os alunos, os resultados se estenderão tanto na escola quanto fora dela.

[...] Na medida em que esses indivíduos se encontram no tempo e espaço determinado pela classe, fazem-se participantes de uma nova relação social.

RC: 42251

Disponível em: https://www.nucleodoconhecimento.com.br/educacao/aprendizagemde-matematica 
Essa relação traz consigo, evidentemente, fortes traços da presença dos indivíduos em suas outras socialidades, em outras palavras: cada um traz para "dentro da sala" suas crenças, ideologias e visões de mundo (ROBLE, 2012, p. 69).

Dessa maneira cresce ainda mais o laço afetivo dessa relação que foi criado na classe, pois, para o aluno, o professor é aquele capaz de the aconselhar, direcionar, compreender, participar de sua vida com o alcance além-escola, olhando para seu professor como um modelo de cidadão autentico, pois não é somente em sala de aula que o docente, como um indivíduo ativo socialmente, estabelece relações para contribuir a algum processo, e esse cotidiano é assistido pelo aluno nesse contexto sem que seja necessário acompanhar os passos do seu professor para saber quais as interações que ele mantém para serem percebidas.

O fato de ter o seu professor como um modelo de agente social, se origina da relação que estes estabelecem em sala de aula e, consequentemente, o aluno estará mais atento aos fenômenos de ensino, criando em si um objetivo a ser conquistado como cidadão e não somente como aluno, pois, conforme Drouet (2006, p. 163):

A personalidade da criança vai se formando à medida que ela interage com o meio físico e social em que vive, desenvolve-se com seu crescimento físico, vai se modificando com as sucessivas interações e se expressa através dos diferentes comportamentos, nos relacionamentos sociais e nas ligações afetivas.

Nesse sentido, o papel do professor é ser um mediador do aluno com o seu meio, permitindo que o aluno perceba-se como um sujeito inserido na sociedade, que exigirá cada vez mais dele, respostas de suas experiências, para que possa estar preparado para contribuir em sua sociedade. Assim, o docente, em sala de aula, busca transmitir saberes que os façam exercitar a capacidade de se pensarem cidadãos. Aqui, o professor passa a ser visto como um agente construtivo de personalidade.

Além disso, em outra situação em sala de aula, o professor é tido como um companheiro para momentos difíceis na resolução de problemas e, nesse sentido,

RC: 42251

Disponível em: https://www.nucleodoconhecimento.com.br/educacao/aprendizagemde-matematica 
os alunos criam uma admiração por ele ser incentivador, sobretudo a partir das dificuldades, por ele ser, acima de tudo, amigo. Essas expressões evidenciam que a ideia de bom professor, presente hoje nos alunos, passa pela capacidade que o professor tem de se mostrar próximo, nesse caso, do ponto de vista afetivo.

Trata-se de o professor se mostrar atento e pronto para ajudar seus alunos em suas dificuldades, pois, "O sujeito sozinho, por melhores que sejam suas potencialidades hereditárias de nada é capaz, da mesma forma que o objeto não pode manifestar suas características sem um sujeito para percebê-las. Na relação, ambos são ativos e indispensáveis" (NOGUEIRA, 2007, p.86).

Além disso, o professor é sempre um suporte para todos os momentos em que o aluno necessitar, ou seja, o papel do professor aqui é de ser atencioso às dificuldades encontradas pelo aluno para solucionar um determinado problema. Neste momento, o docente, para mostrar sua atenção aos alunos, tem a oportunidade de criar um ambiente onde os estudantes se sintam bem à vontade, incentivando-os, orientando-os, estimulando-os e fazendo com que eles se sintam capazes de compreender e aprender.

De acordo com Torisu e Ferreira (2009, p. 171) "Dentre as contribuições que o professor pode oferecer ao seu aluno, para que este tenha um ensino de qualidade e prazeroso, está a tarefa de estimular o desenvolvimento de crenças de autoeficácia mais robustas e favoráveis". Dessa forma, o aluno pode perceber que ele é o centro de sua aprendizagem e que o seu professor é somente um intermediário entre ele e o conhecimento que manifesta, que o estimula e o incentiva a chegar a determinada solução, que se mostra atencioso, compreensivo e amigo.

Portanto, para os alunos, o professor de matemática possui diferentes imagens, mas todas relacionadas entre si, que contribuem eficazmente para maior aquisição de conhecimento, mas também acaba por perceber-se construtor de sua própria aprendizagem, de seu próprio conhecimento, dependendo somente de si e se 
apoiando no seu professor para chegar a um ponto considerável da aprendizagem matemática.

\section{ASPECTOS PRESENTES NA RELAÇÃO PROFESSOR/ALUNO PARA O ENSINO E APRENDIZAGEM DA MATEMÁTICA}

Pensar na relação Professor/Aluno no contexto escolar é sensibilizar-se no explorar dos seus processos e aos fenômenos que a permeiam sem, no entanto, deixar de esclarecer todos os aspectos presentes, mesmo que se alcance aquilo que não era esperado como objetivo, mas pôr a descoberto todos os resultados é o importante aqui, pois, a implicação da relação do professor com o aluno em sala de aula vem se mostrar em diversos aspectos que serão considerados essenciais nessa abordagem.

É de suma importante o docente estabelecer relações e criar laços afetivos com seus alunos para o processo de ensino/aprendizagem, pois além da aproximação afetiva de ambos, cria-se uma aproximação entre as experiências do professor e entre o saber, e dessa forma, o processo de ensino se dá mais eficaz, contribuindo de modo positivo para o mesmo, pois a interação desses fatores gera um ambiente que permite uma confiança maior, tanto no ato de ensinar quanto no ato de aprender, pois, "ao estabelecer laços afetivos com seus alunos, em sala de aula, o professor poderá influenciá-los de modo positivo, proporcionando um ambiente agradável e de confiança mútua" (TORISU E FERREIRA, 2009, p.169).

Além do mais, o docente oferece condições para que o mesmo se manifeste nesse processo, de modo que participe mais ativo no desenvolvimento de seus conhecimentos matemáticos, tendo uma abertura maior para buscar soluções de problemas por conta própria.

[...] É possível imaginar que o docente sempre esteja em condições de propiciar as ferramentas "que faltam" para acabar de elaborar uma ideia, e basicamente é isso mesmo que acontece [...] Diante do novo, os alunos têm de experimentar, explorar, pensar com seus botões (SADOVSKY, 2010, p.57).

RC: 42251

Disponível em: https://www.nucleodoconhecimento.com.br/educacao/aprendizagemde-matematica 
Fazer, portanto, o aluno pensar por si só para a resolução de determinado problema permite a este ser independente, ainda que haja momentos em que seja importante e necessário o docente intermediá-los até os caminhos viáveis e faça-o perceber as saídas.

Assim, entende-se que há uma fenda nesse processo de ensino/aprendizagem, onde o docente faz o aluno se sentir livre na manifestação e na construção de suas próprias ideias, além de criar nos indivíduos, um laço tão forte de amizade e de respeito. "[...] O ideal é o aprender com prazer ou o prazer de aprender, e isso relaciona-se com a postura filosófica do professor, sua maneira de ver o conhecimento, e do aluno - aluno também tem filosofia de vida. Essa é a essência da filosofia da educação"(D’AMBROSIO, 2012, p. 77). Ou seja, a relação professor/aluno favorece para que haja uma interação mais próxima de ambos, onde o docente acaba por ter domínio sobre o aluno, contribuindo melhor para a sua prática. Em outras palavras, a liberdade dada pelo professor ao aluno para se expressar o prende a esse novo jeito de ensinar.

Além disso, compreende-se que o fato de o docente manter relações proximais com seus alunos em sala de aula favorece para que estes se aproximem também do conteúdo e do aprendizado, mas há um fator importante a salientar: a relação estabelecida entre professor e aluno permite gerar também uma relação proximal de alunos com alunos, a qual implicará de forma positiva na construção de conhecimentos e estímulos afetivos da mesma, pois, "além da interação entre professor e aluno, a interação entre alunos desempenha papel fundamental na formação das capacidades cognitivas e afetivas" (BRASIL, 1997, p. 41). Dessa forma, facilita o trabalho em equipe, que desencadeia o desenrolar de novas e várias ideias para solucionar determinado problema.

Quando se pretende abordar um assunto tão amplo, como da relação professor e aluno, não se pode deixar de evidenciar os laços afetivos que se acorrentam nesse processo, porquanto, da mesma forma, a relação aluno/aluno está implicada nesses laços, pois trata-se de fenômenos que envolvem as emoções dos indivíduos e, 
desse modo, as relações aqui citadas são tão fundamentais quanto qualquer outro fator no que tange à aprendizagem de Matemática. Portanto, o peso do clima emocional tem uma importância maior do que todos os demais fatores somados (CASASSUS 2008).

Quando os alunos se aproximam uns dos outros, somando à contribuição do professor, na busca da compreensão de problemas matemáticos, estes se sentem motivados por eles mesmos a encontrarem soluções e, além disso, a autoconfiança de cada um é trabalhada no grupo.

Nesse sentido, os indivíduos sentem-se capazes de encontrar saídas e soluções e, consequentemente a buscar níveis mais elevados de situações propostas e, portanto, essa metodologia é um fator determinante para o aprendizado do aluno, porque faz com que eles se sintam valorizados, sendo, acima de tudo, uma motivação para eles, pois, "pode fazê-los melhorar sua autoestima, suas crenças e suas atitudes por meio de tarefas estimulantes, que, gradativamente, conduzam o aluno a se perceber capaz de solucionar desafios maiores" (TORISU E FERREIRA, 2009, p.169).

Para Casassus (2008, p. 30) "nas instituições em que os alunos se dão bem com os colegas, não há brigas, o relacionamento harmonioso predomina e não há interrupções nas aulas, eles se saem melhor". Apesar disso, quando os alunos se relacionam em sala de aula, pode correr o risco de haver um descontrole na classe, podendo levar o ensino ao fracasso, pois diferentes personalidades entram em conflito, ainda que amigável.

Nesse momento, o professor deve procurar uma forma de manter a ordem e condicionar o ambiente de modo que essa interação seja favorável, ou seja, é dever do professor tentar encontrar uma forma de estabelecer essas relações sem que ocorram tais conflitos, considerando que não se pode deixar de lado a certeza que sempre os ocorrerão. 
[...] ele pode e deve usar sua autoridade para advertir algum jovem por atitudes inadequadas na sala ou em relação a outros colegas [...] é preciso estar preparado para situações inesperadas, encontrando soluções inéditas e criativas em vez de recorrer sempre ao mesmo jeito de ensinar (CASASSUS 2008, p. 30).

Por outro lado, quando a relação que o professor tem com seus alunos não respeita limites, é gerado um problema, onde o aluno, por confiar tanto na sua amizade com o professor, pensa que mesmo que ele não faça as atividades propostas, ele não terá nenhum problema, pois seu professor é seu amigo. "[...] Ao introduzir certo grau de liberdade, os alunos devem usar - com maior ou menor consciência disso - as noções de varável e dependência" (SADOSKY, 2010, p. 59).

Além disso, considera-se também que isso levará o professor a crer que tudo está ocorrendo bem, mesmo que não esteja, pois, se a amizade do aluno com o professor não tem limites, o discente não levará em conta se o que o professor está ensinando está certo ou errado ou, se a metodologia adotada permite maior compreensão do conteúdo, o qual impedirá uma possível correção por ambos os lados, pois é gerado um receio de ofensa e "é exatamente nesse sentido que o ensino não se esgota no 'tratamento' do objeto ou conteúdo, superficialmente feito, mas se alonga à produção das condições em que aprender criticamente é possível" (FREIRE, 2008, p. 26).

Nesse sentido, criticar favorece para o amadurecimento, tanto do docente em relação à sua prática, quanto para o aluno em relação ao seu aprendizado e, dessa forma, se não há críticas construtivas nesse processo, o ensino não se fará completo. Por outro lado, a não criticidade dos fatos pode desencadear, no relacionamento do professor com seus alunos, um desrespeito, considerado como um aspecto negativo para o processo de ensino/aprendizagem, pois se o docente percebe que há alguma falta por parte dos seus alunos e não tentar entender ou não buscar solucionar determinado problema dos mesmos, este estará negando a realidade do aluno e a oportunidade de se fazer um ensino mais eficaz.

RC: 42251

Disponível em: https://www.nucleodoconhecimento.com.br/educacao/aprendizagemde-matematica 
Para Freire (2008, p. 26), "percebe-se, assim, a importância do papel do educador, o mérito da paz com que viva a certeza de que faz parte da sua tarefa docente não apenas ensinar conteúdos, mas também ensinar a pensar certo. Daí a impossibilidade de vir a tornar-se um professor crítico". No entanto, se o aluno percebe que há problemas na prática de seu professor e o mesmo não o critica de modo que este repense seus atos, da mesma forma o aluno estará excluindo a possibilidade de se manifestar ativo nesse processo. Nessa perspectiva podem decorrer maiores consequências, pois, os prejudicados não será quem está cometendo uma falha em sua prática, mas quem depende dela para o aprendizado significativo e para amadurecer como pessoa.

Portanto, compreende-se que a relação professor/aluno implica não só de modo positivo para aquisição de conhecimento, mas poderá ter consequências negativas se essa relação não for bem administrada como parte desse processo, podendo tornar um fator que levará o ensino ao fracasso. Cabe, portanto, ao professor, o desafio de determinar soluções para os impasses presentes e, constantes, no cotidiano escolar, se desempenhar para a superação de todas as dificuldades, que uma hora ou outra, aparecerão com pouca ou grande intensidade.

\section{CONSIDERAÇÕES FINAIS}

Considerando os resultados e as análises percebidas no desenvolvimento deste trabalho, pôde-se identificar no cotidiano escolar alguns fatores que dificultam, enquanto outros que contribuem para o processo de ensino/aprendizagem de matemática. Nesse sentido, destaca-se que o relacionamento do professor tem com seus alunos em sala de aula fornece meios eficazes para a formação, tanto técnica quanto pessoalmente dos indivíduos participantes dessa relação, pois o professor se mostra mais presente na vida escolar do aluno, que por sua vez, espera encontrar na escola uma influência maior para aquilo que anseia futuramente.

O cotidiano escolar apresenta situações que rodeiam o processo de ensino/aprendizagem de Matemática, que impedem que a prática docente, por si só,

RC: 42251

Disponível em: https://www.nucleodoconhecimento.com.br/educacao/aprendizagemde-matematica 
manifeste maiores resultados no que tange ao ensino de Matemática. Tais fatores, como a fragmentação de conhecimentos prévios, o desinteresse de alunos pela disciplina ou até mesmo pelo estudo, são percebidos consideravelmente pelos que participam diretamente nesse contexto, mais especificamente, pelo professor.

No entanto, não basta que o professor tenha a ciência de todas essas situações, é preciso que a relação que este traz com seus alunos favoreça para o desempenho de ambos. Trata-se, portanto, de criar laços afetivos entre os indivíduos, que a mesma influenciará positivamente no ensino e aprendizagem. Dessa forma, o professor se apresenta como um agente ativo no desenvolvimento do aluno, fazendo com que a metodologia adotada seja aceita positivamente, de modo que estes permitam acontecer o processo de interação, levando a um melhor desenvolvimento cognitivo do aluno e contribuindo no processo de ensino e aprendizagem de Matemática, assim como à prática docente.

Por outro lado, quando essa interação não atende a certos limites de aproximação, a mesma pode se tornar um obstáculo a ser contornado. Dentro desse limiar, tem-se uma questão cheia de complexidades a ser analisada, pois essa pode ser uma das respostas para uma educação de qualidade, penetrando no emocional do aluno e criando neles laços afetivos que os faça se aproximar não somente das pessoas, mas, sobretudo do conhecimento. Por ser um assunto muito delicado, exige um olhar mais cauteloso, que abranja um horizonte além daquilo exposto e, que permita um alcance além-escolar na sociedade.

Não se exclui, portanto, que a relação professor/aluno no contexto escolar seja eficaz para o ensino da Matemática, mas trata-se de manifestar possibilidades de limites sem contorcê-la em sua magnitude, pois a mesma abrange teores ocultos aos olhares de quem se manifesta nela. Trata-se de impor um conhecimento abstrato, mas que é sentido fortemente no desenvolvimento cognitivo e sociocultural do aluno. 


\section{REFERÊNCIAS}

BRASIL. Secretaria de Educação Fundamental. Parâmetros Curriculares nacionais: matemática - 3ํed. Brasília- MEC 1997.

CASASSUS, Juan. O clima emocional é essencial para haver aprendizagem. Revista Nova Escola. ํㅡㄹ 218. Dezembro de 2008.

D’ABROSIO, Ubiratan. Educação Matemática: Da teoria à prática. $23^{\circ}$ ed. Campinas, SP: Papirus, 2012.

DROUET, Ruth caribé da Rocha. Distúrbios da Aprendizagem. São Paulo-SP. 4 ed. Ed. Ática. 2006.

FREIRE, Paulo. Pedagogia da Autonomia: saberes necessários à prática educativa. 37ํe․ São Paulo-SP: Paz e Terra, 2008.

GUERRA, Leonor B; COSENZA, Ramon M. Neurociência e Educação: como o cérebro aprende. Porto Alegre-RS. Artmed, 2011.

NOGUEIRA, Clélia Maria Ignatius. As teorias da aprendizagem e suas implicações no ensino de Matemática. Maringá, vol. 29, n. 1, p. 83-92. 2007.

ROBLE, Odilon. Escola e Sociedade. Curitiba, PR: IESDE Brasil, 2012.

SADOVSKY, Patrícia. O Ensino da Matemática hoje: enfoques, sentidos e desafios. 1 ed. São Paulo-SP: Ática, 2010.

TORISÚ, Edmilson Minoru; FERREIRA, Ana Cristina. A teoria social cognitiva e o ensino-aprendizagem da Matemática: considerações sobre as crenças de autoeficácia matemática. Ciências e Cognição. Ouro Preto-MG Vol. 14, p 168-177. 2009. 
Enviado: Outubro, 2019.

Aprovado: Dezembro, 2019.

Disponível em: https://www.nucleodoconhecimento.com.br/educacao/aprendizagemde-matematica 